were healthy outside the margin of the tumour. Pieces of the tumour were hardened in spirit, mounted in the usual way, and examined microscopically, which showed that the tumour was composed of fibrous tissue. The heart was healthy, but seemed loose and flabby. Kidneys soft and friable, apparently undergoing fatty changes.

\title{
SCLEROSTOMA ARMATUM IN THE SPERMATIC CORD.
}

\section{By W. Selborne Worthington, M.R.C.V.S., Wigan.}

WHILE castrating a grey two-year-old cart colt on 3 rd June, I came across a specimen of the agamous form of the sclerostoma armatum in a rather uncommon position.

On the inner surface of the posterior or fibrous portion of the right spermatic cord, a little above the globus minor of the epididymis, was a tube composed apparently of white fibrous tissue, about threesixteenths of an inch thick and one and an eighth inch long, situated immediately beneath the serous covering of the cord, and standing out distinctly above the surrounding level. The tube was disposed in an oblique direction downwards and backwards, terminating at its lower extremity about three-quarters of an inch above the globus minor. It was open at both ends and contained an agamous sclerostoma armatum of about the same length. The parasite was undergoing degenerative changes, being very soft and friable.

I sent the specimen to Professor Stockman who examined it, and identified it as the agamous form of the sclerostoma armatum. The colt, though in poor condition, is and has been apparently in good health, and the farm on which he has been reared has never been suspected of harbouring these parasites.

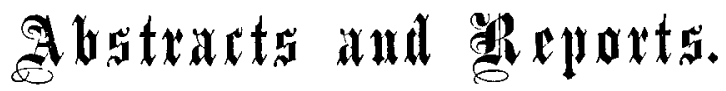

\section{MEAT POISONING.}

IN the spring of the present year, in the Canton Thurgau, numerous persons fell ill after having partaken of pork that had been smoked. The flesh, it was alleged, came from animals that had been killed while seriously ill, the symptoms exhibited being redness of the skin and gastro-intestinal catarrh. Seven persons who had partaken of this flesh were during the following day attacked with gastro-intestinal catarrh, and one child, aged four years, died after two days, with profuse diarrhœa and cramp-like contractions.

No symptoms of disturbance were produced in animals fed with the flesh in question, but, on the contrary, the intraperitoneal injection of cultures obtained from the discharges of one of the patients and from the flesh were always fatal. In the discharges from the patients and in the suspected flesh there was present a short motile bacillus with rounded ends. The case 